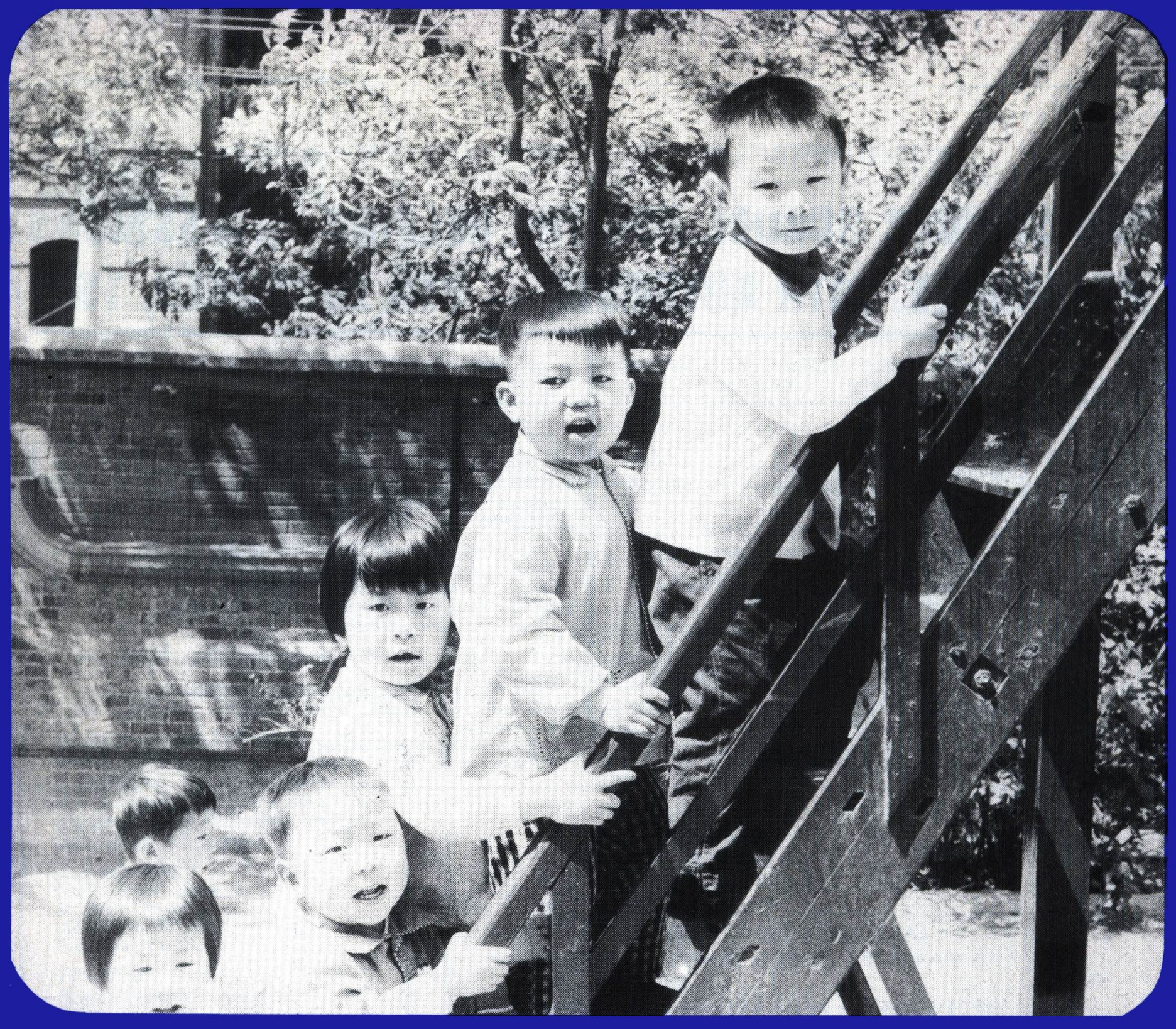

\title{
In this issue....
}

$\star$ Foster care for the handicapped

$\star$ Artificial insemination

$\star$ Special series on migrant issues including, "Culture Shock Can Hurt". by Al Grassby

Also ....

$\star$ Lorne Conference Supplement - July '77

Vol. 1., No. 7,
September, 1977

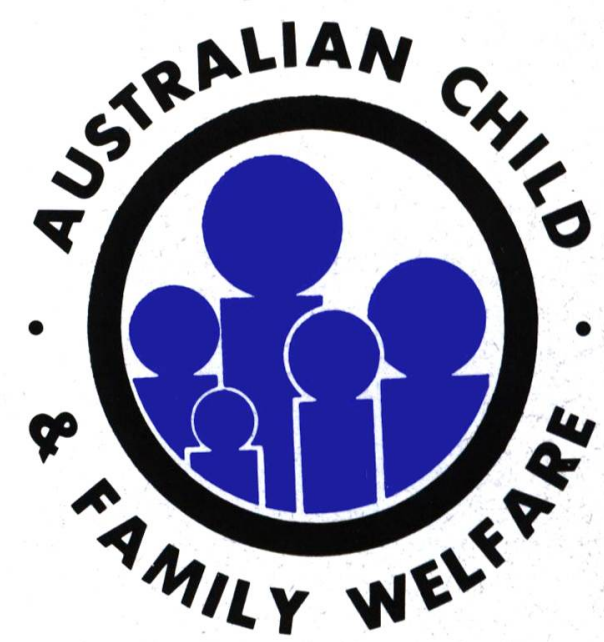

Registered at the G.P.O. for transmission as a Publication - category " $A$ ". 
This year nine workshops are offered in the Summer School, covering a broad range of topics relevant to the helping professions.

The programme for the Summer School is as follows:

Week 1 Group Workshop.

Community Organisation Workshop.*

Demystification of Research in the Helping Professions.

Week 2 Basic Helping Skills:

Interpersonal Relationships and Interviewing

Understanding Small Group Behaviour

Demystification of Monitoring and Evaluation in the Helping Professsions. *

Week 3 Counselling Methods Workshop.

Family Process Workshop.

Organisational and Administrative Aspects of the Helping Professions. *

- These courses are non-residential; the rest are residential.

The group and family workshops will run for $5 \frac{1}{2}$ days, and the other courses for 5 days each.
All workshops will be strongly oriented to the acquisition of practical skills, although theoretical input will also be provided. A variety of teaching/learning methods will be used. Most courses are open to both professionals and voluntary workers.

The staffing of courses will involve lecturers at P.I.T. School of Social Work as well as experienced practitioners from outside the School. Staff will include the following:

Phill Boas, Peter Brennan, Claire Bundey Jim Crawley, Frances Donovan, Valerie Gerrand, Fay Marles, Vivienne McCutcheon, Peter Redding, Margaret Topham. Alf Wesson and Jerry Winston.

A detailed brochure and application forms are available from:

Ms. Maureen Ryan, Summer School 1977

School of Social Work, Preston Institute of Technology,

Plenty Road, BUNDOORA, 3083.

Phone: 4673211
National Library of Australia

Card No. and ISSN No. 03128970

Photographs:-

Andrew Blake, Colin Knox,

Robert Ashton/Scoopix, Howard Birnstihl

Pauline Reynolds 


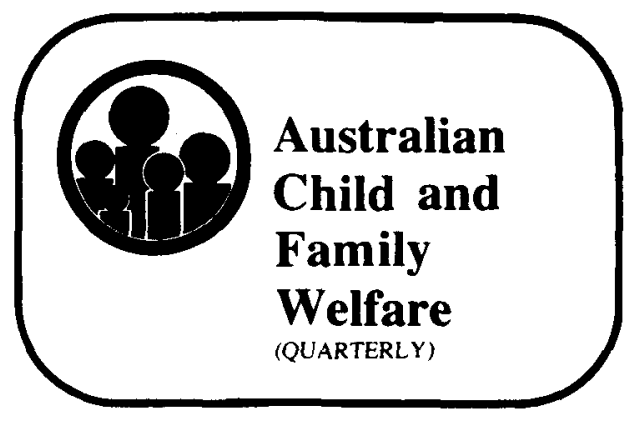

\section{In this}

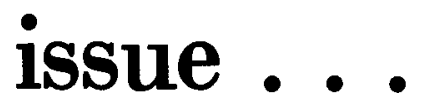

IN THIS ISSUE

POT POURRI $\ldots \ldots \ldots \ldots \ldots \ldots \ldots \ldots \ldots \ldots \ldots, 2$

EDITORIAL $\ldots \ldots \ldots \ldots \ldots \ldots \ldots \ldots \ldots \ldots, 3$

NOTES TO CONTRIBUTORS $\ldots \ldots \ldots \ldots \ldots \ldots \ldots, 4$

CULTURE SHOCK CAN HURT-

Hon A. J. Grassby .................. 5

FOSTER CARE FOR INTELLECTUALLY

HANDICAPPED CHILDREN

Jill Volard \& Frank Forrest ............... 11

THE LORNE PAPERS

Reports of the 1977 Victorian Child Care Conference 19

AUSTRALIAN CHILD AND

*VICTORIAN PLAYGROUP ASSOCIATION .... 21

FAMILY WELFARE is the quarter-

ly journal of the Child and Family

Welfare Council of Australia and is

published by the Children's Welfare

Association of Victoria.

\section{ADVERTISING}

Geoff Goullet, Suite 2,

65 Queens Road,

MELBOURNE. 3004.

Telephone 516238.

\section{PRINTER:}

Pilgrim Printing Services,

11 Sheridan Court, Heathmont,

Victoria, 3135.

Telephone: 7295828.

*SOUTHERN REGIONAL CHILD

CARE CO-OPERATIVE............... 24

*THE DEVELOPMENT OF COMMUNITY

TREATMENT $\ldots \ldots \ldots \ldots \ldots \ldots \ldots \ldots \ldots, \quad 28$

*HARTNETT HOUSE FAMILY CENTRE....... 36

*COPELEN STREET FAMILY CENTRE_ 40

*FAMILY DAY CARE

FACING DECISION IN AN ARTIFICIAL

INSEMINATION BY DONOR PROGRAMME-

Alison Bonython

IMMIGRANT ADOLESCENTS AND CULTURE

CONFLICT -

Joan Snyder

\section{Universal Children's Day}

Wednesday, October, 26th 